\title{
Intakes of folate, methionine, vitamin B6, and vitamin B12 with risk of esophageal and gastric cancer in a large cohort study
}

\author{
Q Xiao*,1, N D Freedman ${ }^{1}$, J Ren ${ }^{2}$, A R Hollenbeck ${ }^{3}$, C C Abnet ${ }^{1}$ and Y Park ${ }^{1}$ \\ ${ }^{1}$ Nutritional Epidemiology Branch, Division of Cancer Epidemiology and Genetics, National Cancer Institute, Bethesda, Maryland, \\ USA; ${ }^{2}$ National Office for Cancer Prevention and Control, National Cancer Center, Beijing, China and ${ }^{3}$ AARP, Washington, District \\ of Columbia, USA
}

Background: Nutrients in the one-carbon metabolism pathway may be involved in carcinogenesis. Few cohort studies have investigated the intakes of folate and related nutrients in relation to gastric and esophageal cancer.

Methods: We prospectively examined the association between self-reported intakes of folate, methionine, vitamin B6, and vitamin B12 and gastric and esophageal cancer in 492293 men and women.

Results: We observed an elevated risk of esophageal squamous cell carcinoma with low intake of folate (relative risk (95\% confidence interval): Q1 vs Q3, $1.91(1.17,3.10))$, but no association with high intake. Folate intake was not associated with esophageal adenocarcinoma, gastric cardia adenocarcinoma, or non-cardia gastric adenocarcinoma. The intakes of methionine, vitamin B6, and vitamin B12 were not associated with esophageal and gastric cancer.

Conclusion: Low intake of folate was associated with increased risk of esophageal squamous cell carcinoma.

Folate is critically involved in DNA synthesis, repair, and methylation. Folate deficiency may lead to genetic mutation, chromosomal damage, and altered epigenetic modification (Ulrich, 2007). Previous studies have linked folate deficiency with elevated risk of colorectal cancer (Robinson et al, 2013) and breast cancer (Kamangar et al, 2009; Stevens et al, 2010; Shrubsole et al, 2011). The link between folate intake and esophageal and gastric cancer remain unclear (Larsson et al, 2006). All but two studies on folate and esophageal or gastric cancer are case-control in design, making them potentially susceptible to recall bias. Moreover, many previous studies did not distinguish between subtypes of esophageal cancer and gastric cancer. In addition to folate, other nutrients such as methionine, vitamin B6, and vitamin B12 are key elements of the one-carbon metabolism pathway and may also influence cancer risk. (Bailey, 2003). Few studies, however, have assessed these associations. Finally, alcohol consumption and smoking may impair folate status (Bailey, 2003, Li et al, 2013), yet it also remains unclear how alcohol and smoking may modulate potential associations between folate and these cancers.
Given the limitations of previous investigations, we studied the intake of folate, methionine, vitamin B6, and vitamin B12 in relation to the risk of esophageal squamous cell carcinoma (ESCC), esophageal adenocarcinoma (EAC), gastric cardia adenocarcinoma (GCA), and non-cardia gastric adenocarcinoma (NCGA) in a large cohort of nearly 500000 US men and women.

\section{MATERIALS AND METHODS}

Details of the NIH-AARP Diet and Health Study were reported previously (Schatzkin et al, 2001). In brief, AARP members who were 50-71-years old in eight states were recruited in 1995-1996. Of the 566398 participants who satisfactorily completed the baseline questionnaire, we excluded proxy respondents $(n=15760)$ and those who had cancer other than nonmelanoma skin cancer $(n=51234)$ or self-reported end-stage renal disease at baseline $(n=986)$. Additionally, we excluded individuals reporting 
extreme intakes ( $>2$ times the interquartile ranges) of total energy $(n=4416)$ and dietary folate, methionine, vitamin B6, or vitamin B12 $(n=1710)$. The analytical cohort consisted of 492292 men and women. The study was approved by the National Cancer Institute Special Studies Institutional Review Board, and informed consent was implied by completing the questionnaire.

Incident cancer cases were identified through linkage to cancer registries in eight original states and three additional states that our participants tended to move. Cases were defined using the International Classification of Diseases for Oncology, Third Edition (ICD-O-3) (Esophageal cancer: C15.0-15.9; Gastric cancer: C16.0 (GCA) and C16.1-16.7 (NCGA)). The esophageal cancer cases were further classified into ESCC (code: 8050-8076) and EAC (code: 8140, 8142, 8144, 8261, 8310, 8480, 8481, 8570, 8260, 8263 , and 8490). We followed cohort members periodically for change of address using the National Change of Address database maintained by the US Postal Service, other address change update services, and direct reports from participants. During the followup, $5 \%$ of participants were no longer living within the 11 states and were therefore outside of our cancer catchment areas.

The frequency and amount of dietary intakes were assessed at baseline using a self-administered 124-item food-frequency questionnaire (FFQ). The food items, portion sizes, and nutrient database were constructed using the US Department of Agriculture's 1994-1996 Continuing Survey of Food Intakes (Subar et al, 2000). Dietary intakes were adjusted for total energy intake using the residual method (Willett and Stampfer, 1986). Previous validation study found that the energy-adjusted correlation coefficients between intakes measured from the FFQ and 24-h dietary recalls were moderate to high: the correlation coefficients for folate, vitamin B6, and vitamin B12 were $0.64,0.69$, and 0.47 in men and $0.69,0.70$, and 0.47 in women, respectively (Thompson et al, 2008). The baseline questionnaire also collected information on how frequent participants took multivitamins, which contained $400 \mathrm{mcg}$ folate. Total intakes of folate, vitamin B6, and vitamin B12 were calculated by combining supplemental and dietary intakes.

We estimated relative risks (RRs) and two-sided 95\% confidence intervals (CIs) with the Cox proportional hazards model (SAS 9.3; SAS Institute, Cary, NC, USA). We evaluated and confirmed the proportional hazards assumption for the main exposures by including interaction terms with time and using the Wald $\chi^{2}$ procedure to test if coefficients equaled zero. Person-years of follow-up time were calculated from the baseline until cancer diagnosis, relocation from the registry areas, death, or the end of follow-up (31 December 2006), whichever came sooner. Multivariate models were adjusted for risk factors that are potential confounders, including age, sex, race, education, marital status, health status, BMI, smoking status, smoking dose, time since quitting, physical activity, alcohol, multivitamin use, family history of cancer, and total caloric intake. To test for linear trend across quintiles and categories of intake, we used the median value of each quintile or category as a continuous variable in the regression models.

\section{RESULTS}

During 4471303 person-years of follow-up, we identified 185 ESCC, 574 EAC, 424 GCA, and 515 NCGA cases. Participant characteristics by quintiles of dietary folate and methionine intake are presented in Supplementary Table S1. Participants with high intakes of dietary folate were more likely to be college educated, report excellent health, exercise $\geqslant 5$ times per week, and use multivitamin supplements but less likely to be current smokers; they consumed more fruits and vegetables and whole grains but less alcohol. Participants with high intakes of dietary methionine had higher BMI and education but lower alcohol intake.
The median intake of dietary folate in the third quintile was $405 \mathrm{mcg}$ per day, which is approximately the daily recommended amount in the US. Using the third quintile as the reference, lower intakes of folate were associated with increased risk of ESCC (RR first Q vs third Q: 1.91, 95\% CI, 1.17-3.10), but higher intakes of folate were not related to risk of ESCC (Table 1). Higher intakes of folate, methionine, vitamin B6, or vitamin B12 were not associated with either ESCC risk or EAC risk. Furthermore, dietary intakes of folate, methionine, vitamin B6, or vitamin B12 were not associated with the risk of developing either GCA or NCGA (Table 2). Excluding cancer cases diagnosed within 3 years following baseline had little impact on the findings (data not shown). In subgroup analysis by alcohol and smoking (Supplementary Table S2), the elevated risk of ESCC with low intake of folate appeared to be stronger among people who consumed alcohol $\geqslant 15 \mathrm{~g}$ per day or who were current or former smokers. However, these differences did not show a significant interaction between folate intake and alcohol consumption $(P=0.19)$ or smoking $(P=0.45)$.

We evaluated the risks of ESCC and EAC in relation to total folate intake, combining both dietary and supplemental folate (Figure 1). There was a significant inverse association between total folate intake and ESCC risk $(P$ for trend $=0.003$ ), but only the lowest category was associated with a significant increase in risk. In contrast, there was no association between total folate intake and EAC risk $(P=0.15)$. We also evaluated total vitamin B6 and vitamin B12 in relation to ESCC risk. Vitamin B6 was inversely associated with ESCC risk ( $P$ for trend: 0.01 ), but none of the individual RR estimates was significant. Vitamin B12 was not associated with ESCC risk (data not shown).

\section{DISCUSSION}

In this large prospective cohort study, we found that low intake of folate was associated with elevated risk of ESCC, but folate intake higher than the recommended amount may not offer additional protection over ESCC. Intakes of methionine, vitamin B6, or vitamin B12 were not associated with esophageal or gastric cancer risk.

Our study is the first cohort analysis of the relationship between folate intake and esophageal cancer risk. Our finding of positive association between low folate intake and higher risk of ESCC is largely consistent with previous case-control studies (La Vecchia et al, 1994; Zhang et al, 1997; Brown et al, 1988; Lopez-Carrillo et al, 1999; Botterweck et al, 2000; Jessri et al, 2011; Zhao et al, 2011; Ibiebele et al, 2011). In contrast, although three of the five earlier case-control studies (Brown et al, 1988, 1995; Munoz et al, 2001; Kim et al, 2005; Ibiebele et al, 2011) found a significant inverse association between folate intake and EAC risk, our study did not find a significant relationship between EAC and dietary folate.

Our finding of a null association between dietary folate and gastric cancers is most comparable to that of the two cohort studies. The Netherlands Cohort Study found a relative risk of 0.9 (95\% CI, 0.6-1.3) among those in the highest quintile of dietary folate intake, compared with those in the lowest (Cook et al, 2010). Similarly, a more recent study examined stomach cancer risk in relation to dietary folate intake in the Swedish Mammography Cohort and reported no association between the two (RR (95\% CI), $1.04(0.61,1.86))$ (Bailey, 1990). However, neither of these two studies distinguished GCA from NCGA.

It has been postulated that there might be a nonlinear relation between folate intake and cancer risk, with the optimal cancerpreventive effect achieved at moderate folate status while both low and excessively high intake associated with enhanced carcinogenesis and tumor growth (Ulrich, 2007). We found an inverse 
Table 1. Age-adjusted and multivariate RRs and $95 \% \mathrm{Cls}$ of risk of esophageal squamous cell carcinoma and esophageal adenocarcinoma for quintiles of dietary folate, methionine, and vitamin B6 intake in the NIH-AARP study

\section{Quintile}

\begin{tabular}{|l|l|l|l|l|l|l|}
\hline & Q1 & Q2 & Q3 & Q4 & Q5 & $P$ for trend \\
\hline
\end{tabular}

\section{Esophageal squamous cell carcinoma}

\section{Folate}

Median intake, mcg per day

No. of cases

Age-adjusted RR

Multivariate $\mathrm{RR}^{\mathrm{a}}$

\begin{tabular}{c|c|c|c|c|c}
288 & 353 & 405 & 463 & 566 & 21 \\
70 & 43 & 23 & 28 & $0.90(0.50,1.62)$ & $<0.001$ \\
$3.25(2.03,5.21)$ & $1.91(1.15,3.18)$ & Ref. & $1.21(0.69,2.09)$ & $1.07(0.59,1.94)$ & 0.02 \\
$1.91(1.17,3.10)$ & $1.59(0.95,2.64)$ & Ref. & $1.33(0.77,2.32)$ & 1.07 &
\end{tabular}

\section{Methionine}

Median intake, g per day

No. of cases

Age-adjusted RR

Multivariate $\mathrm{RR}^{\mathrm{a}}$

\section{Vitamin B6}

1.1

62

$2.28(1.45,3.59)$

$1.45(0.91,2.31)$

1.3

41

$1.50(0.93,2.44)$

$1.34(0.82,2.18)$

\begin{tabular}{c|c}
1.5 & 1.7 \\
27 & 32 \\
Ref. & $1.20(0.72,2.00)$ \\
Ref. & $1.30(0.78,2.16)$
\end{tabular}

2.0

23

$0.89(0.51,1.55)$

$1.02(0.58,1.78)$

\section{4}

65

$2.01(1.33,3.04)$

$1.38(0.91,2.12)$

\section{7}

39

$1.17(0.74,1.86)$

$1.08(0.68,1.71)$
2.2

22

$0.63(0.37,1.08)$

$0.70(0.41,1.19)$
2.7

25

$0.70(0.42,1.17)$

$0.86(0.51,1.45)$

Multivariate $\mathrm{RR}^{\mathrm{a}}$

$<0.001$

0.01
2.5

53

$1.56(1.01,2.49)$

$1.21(0.78,1.87)$

\section{6}

39

$1.15(0.72,1.82)$

$1.06(0.67,1.68)$
Age-adjusted RR

Multivariate $\mathrm{RR}^{\mathrm{a}}$

\section{Esophageal adenocarcinoma}

\section{Folate}

No. of cases

Age-adjusted RR

Multivariate $\mathrm{RR}^{\mathrm{a}}$

\section{Methionine}

No. of cases

Age-adjusted RR

Multivariate $\mathrm{RR}^{\mathrm{a}}$

\section{Vitamin B6}

No. of cases

Age-adjusted RR

Multivariate $\mathrm{RR}^{\mathrm{a}}$

\section{3}

$1.51(1.19,1.92)$

$1.23(0.96,1.57)$

111

$0.99(0.76,1.28)$

$0.90(0.70,1.17)$
5.4

31

$0.91(0.56,1.48)$

$0.96(0.59,1.56)$
7.3

28

$0.82(0.50,1.35)$

$0.85(0.52,1.41)$
113

$0.88(0.68,1.13)$

$0.94(0.73,1.22)$
108

$0.84(0.65,1.08)$

$0.87(0.67,1.12)$

115
Ref.
Ref.

87

$0.75(0.57,0.99)$

$0.81(0.61,1.06)$

\section{8}

$0.84(0.64,1.10)$

$1.00(0.76,1.31)$

\section{Vitamin B12}

No. of cases

Age-adjusted RR

Multivariate $\mathrm{RR}^{\mathrm{a}}$

Abbreviations: $\mathrm{Cl}=$ confidence interval; $\mathrm{NIH}-\mathrm{AARP}=$ National Institutes of Health—American Association of Retired Persons; RR $=$ relative risk.

${ }^{\text {a }}$ Adjusted for age at baseline (continuous); sex (male and female); race/ethnicity (non-Hispanic white, non-Hispanic, black, and others); education (less than high school, high school graduate, some college and college graduate/postgraduate); marital status (married, not married); health status (excellent, very good, good, fair, and poor); body mass index ( $<18.5,18.5-<25,25-<30$, $30-<35, \geqslant 35 \mathrm{~kg} \mathrm{~m}^{-2}$ ); smoking status (never, former, and current); smoking dose $(0,1-10,11-20,21-30,31-40,41-50,51-60$, and $>60$ cigarettes per day); time since quitting (never quit, $\geqslant 10$, $5-9,1-4,<1$ years); vigorous physical activity (never/rarely; $\leqslant 3$ times per month; $1-2,3-4$, and $\geqslant 5$ times per week); alcohol $(0,<5,5-<15,15-<30$, and $\geqslant 30 \mathrm{~g}$ per day); multivitamin use (nonuse, less than daily use, and daily use); family history of any cancer (yes or no); and total caloric intake (continuous).

association only among people in the lower quintiles, and no additional reduction in risk in the higher quintiles. Unfortunately, we were not able to evaluate the effect of even higher intake of folate due to relatively few subjects with a total folate intake $>800 \mathrm{mcg}$ per day and therefore cannot rule out the possibility that very high intake of folate may lead to increased risk. 
Table 2. Age-adjusted and multivariate RRs and $95 \% \mathrm{Cls}$ of risk of gastric cardia adenocarcinoma and non-cardia gastric adenocarcinoma for quintiles of dietary folate, methionine, and vitamin B6 intake in the NIH-AARP study

\section{Quintile}

\begin{tabular}{|c|c|c|c|c|c|c|}
\hline & Q1 & Q2 & Q3 & Q4 & Q5 & Pfor trend \\
\hline \multicolumn{7}{|c|}{ Gastric cardia andenocarcinoma } \\
\hline \multicolumn{7}{|l|}{ Folate } \\
\hline $\begin{array}{l}\text { No. of cases } \\
\text { Age-adjusted RR } \\
\text { Multivariate RR }\end{array}$ & $\begin{array}{c}110 \\
1.37(1.03,1.81) \\
1.12(0.84,1.50)\end{array}$ & $\begin{array}{c}85 \\
1.01(0.75,1.37) \\
0.93(0.69,1.26)\end{array}$ & $\begin{array}{c}86 \\
\text { Ref. } \\
\text { Ref. }\end{array}$ & $\begin{array}{c}67 \\
0.77(0.56,1.06) \\
0.82(0.59,1.12)\end{array}$ & $\begin{array}{c}76 \\
0.87(0.64,1.18) \\
0.98(0.72,1.34)\end{array}$ & $\begin{array}{c}<0.001 \\
0.30\end{array}$ \\
\hline \multicolumn{7}{|l|}{ Methionine } \\
\hline $\begin{array}{l}\text { No. of cases } \\
\text { Age-adjusted RR } \\
\text { Multivariate RR }\end{array}$ & $\begin{array}{c}78 \\
0.82(0.61,1.10) \\
0.82(0.61,1.12)\end{array}$ & $\begin{array}{c}77 \\
0.80(0.59,1.08) \\
0.82(0.61,1.11)\end{array}$ & $\begin{array}{c}95 \\
\text { Ref. } \\
\text { Ref. }\end{array}$ & $\begin{array}{c}83 \\
0.89(0.66,1.19) \\
0.87(0.65,1.16)\end{array}$ & $\begin{array}{c}91 \\
1.00(0.75,1.33) \\
0.93(0.70,1.25)\end{array}$ & $\begin{array}{l}0.15 \\
0.42\end{array}$ \\
\hline \multicolumn{7}{|l|}{ Vitamin B6 } \\
\hline $\begin{array}{l}\text { No. of cases } \\
\text { Age-adjusted RR } \\
\text { Multivariate RR }\end{array}$ & $\begin{array}{c}102 \\
1.41(1.05,1.90) \\
1.28(0.95,1.74)\end{array}$ & $\begin{array}{c}98 \\
1.32(0.98,1.78) \\
1.26(0.93,1.70)\end{array}$ & $\begin{array}{c}76 \\
\text { Ref. } \\
\text { Ref. }\end{array}$ & $\begin{array}{c}80 \\
1.03(0.75,1.41) \\
1.07(0.79,1.47)\end{array}$ & $\begin{array}{c}68 \\
0.85(0.61,1.18) \\
0.92(0.66,1.27)\end{array}$ & $\begin{array}{c}<0.001 \\
0.02\end{array}$ \\
\hline \multicolumn{7}{|l|}{ Vitamin B12 } \\
\hline $\begin{array}{l}\text { No. of cases } \\
\text { Age-adjusted RR } \\
\text { Multivariate RR }\end{array}$ & $\begin{array}{c}73 \\
0.89(0.65,1.22) \\
0.99(0.72,1.37)\end{array}$ & $\begin{array}{c}89 \\
1.08(0.80,1.46) \\
1.12(0.83,1.51)\end{array}$ & $\begin{array}{c}82 \\
\text { Ref. } \\
\text { Ref. }\end{array}$ & $\begin{array}{c}86 \\
1.05(0.78,1.42) \\
1.02(0.76,1.39)\end{array}$ & $\begin{array}{c}94 \\
1.14(0.85,1.54) \\
1.09(0.81,1.47)\end{array}$ & $\begin{array}{l}0.17 \\
0.73\end{array}$ \\
\hline \multicolumn{7}{|c|}{ Non-cardia gastric adenocarcinoma } \\
\hline \multicolumn{7}{|l|}{ Folate } \\
\hline $\begin{array}{l}\text { No. of cases } \\
\text { Age-adjusted RR } \\
\text { Multivariate RR }\end{array}$ & $\begin{array}{c}103 \\
1.18(0.89,1.56) \\
1.05(0.79,1.40)\end{array}$ & $\begin{array}{c}111 \\
1.20(0.92,1.58) \\
1.15(0.87,1.51)\end{array}$ & $\begin{array}{c}95 \\
\text { Ref. } \\
\text { Ref. }\end{array}$ & $\begin{array}{c}97 \\
1.01(0.76,1.34) \\
1.02(0.77,1.35)\end{array}$ & $\begin{array}{c}109 \\
1.12(0.85,1.48) \\
1.12(0.85,1.48)\end{array}$ & $\begin{array}{l}0.49 \\
0.89\end{array}$ \\
\hline \multicolumn{7}{|l|}{ Methionine } \\
\hline $\begin{array}{l}\text { No. of cases } \\
\text { Age-adjusted RR } \\
\text { Multivariate RR }\end{array}$ & $\begin{array}{c}114 \\
1.15(0.88,1.51) \\
1.06(0.80,1.39)\end{array}$ & $\begin{array}{c}109 \\
1.10(0.83,1.44) \\
1.08(0.82,1.42)\end{array}$ & $\begin{array}{c}98 \\
\text { Ref. } \\
\text { Ref. }\end{array}$ & $\begin{array}{c}110 \\
1.14(0.87,1.50) \\
1.15(0.87,1.50)\end{array}$ & $\begin{array}{c}84 \\
0.91(0.68,1.21) \\
0.89(0.66,1.19)\end{array}$ & $\begin{array}{l}0.16 \\
0.34\end{array}$ \\
\hline \multicolumn{7}{|l|}{ Vitamin B6 } \\
\hline $\begin{array}{l}\text { No. of cases } \\
\text { Age-adjusted RR } \\
\text { Multivariate } R^{a}\end{array}$ & $\begin{array}{c}111 \\
1.29(0.98,1.69) \\
1.17(0.88,1.55)\end{array}$ & $\begin{array}{c}114 \\
1.27(0.97,1.68) \\
1.24(0.94,1.63)\end{array}$ & $\begin{array}{c}92 \\
\text { Ref. } \\
\text { Ref. }\end{array}$ & $\begin{array}{c}89 \\
0.94(0.70,1.26) \\
0.96(0.72,1.29)\end{array}$ & $\begin{array}{c}109 \\
1.11(0.84,1.46) \\
1.13(0.86,1.50)\end{array}$ & $\begin{array}{l}0.09 \\
0.43\end{array}$ \\
\hline \multicolumn{7}{|l|}{ Vitamin B12 } \\
\hline $\begin{array}{l}\text { No. of cases } \\
\text { Age-adjusted RR } \\
\text { Multivariate } \text { RR }^{\mathrm{a}}\end{array}$ & $\begin{array}{c}103 \\
1.17(0.88,1.56) \\
1.10(0.83,1.47)\end{array}$ & $\begin{array}{c}117 \\
1.33(1.01,1.75) \\
1.32(1.00,1.73)\end{array}$ & $\begin{array}{c}88 \\
\text { Ref. } \\
\text { Ref. }\end{array}$ & $\begin{array}{c}92 \\
1.05(0.78,1.40) \\
1.06(0.79,1.41)\end{array}$ & $\begin{array}{c}115 \\
1.30(0.98,1.72) \\
1.27(0.96,1.68)\end{array}$ & $\begin{array}{l}0.79 \\
0.60\end{array}$ \\
\hline $\begin{array}{l}\text { Abbreviations: } \mathrm{Cl}=\mathrm{cc} \\
\text { a Adjusted for age at } \\
\text { some college and col } \\
30-<35, \geqslant 35 \mathrm{~kg} \mathrm{~m}^{-2} \\
5-9,1-4,<1 \text { years); } \\
\text { (nonuse, less than daa }\end{array}$ & $\begin{array}{l}\text { l; NIH-AARP = Natic } \\
\text { ous); sex (male and } \\
\text { stgraduate); marital } \\
\text { (never, former, and } \\
\text { activity (never/rarel } \\
\text { use); family history }\end{array}$ & $\begin{array}{l}\text { tes of Health-Ame } \\
\text { ce/ethnicity (non-His } \\
\text { ried, not married); } \\
\text { noking dose }(0,1-10 \\
\text { s per month; } 1-2,3 \\
\text { cer (yes or no); and }\end{array}$ & $\begin{array}{l}\text { sociatio } \\
\text { nite, nor } \\
\text { atus (ex } \\
21-30, \\
\geqslant 5 \text { tim } \\
\text { oric int }\end{array}$ & $\begin{array}{l}\text { ed Persons; RR = relat } \\
\text { c, black, and others); } \\
\text { ery good, good, fair, a } \\
-50,51-60 \text {, and }>60 \\
\text { eek); alcohol }(0,<5,5 \\
\text { inuous). }\end{array}$ & $\begin{array}{l}\text { (less than high schoo } \\
; \text { body mass index }(<1 \\
\text { per day); time since } 9 \\
5-<30 \text {, and } \geqslant 30 \mathrm{~g} \text { pe }\end{array}$ & $\begin{array}{l}\text { school graduate } \\
8.5-<25,25-<30 \\
\text { g (never quit, } \geqslant 10 \\
; \text {; multivitamin use }\end{array}$ \\
\hline
\end{tabular}

Our study had several limitations. First, we could not exclude the possibility that the observed association between folate and ESCC was due to residual confounding. People with low folate intake tended to have unhealthy behaviours, which may also affect esophageal and gastric cancer risk. Second, diet sources rich in folate contain other nutrients that may influence the development of esophageal and gastric cancer. A recent study in the NIH-AARP Health and Diet Study showed that dietary patterns with high intake of plant-based food sources, evaluated by high scores of Healthy Eating Index-2005 and alternate Mediterranean Diet, were inversely associated with ESCC risk (Li et al, 2013). Third, we lacked information on important factors such as gastroesophageal reflux disease and Helicobacter pylori infection status among participants, both of which are known strong risk factors for esophageal and gastric cancer. Finally, we lacked information on the use of individual folate supplements. Our study also has several 

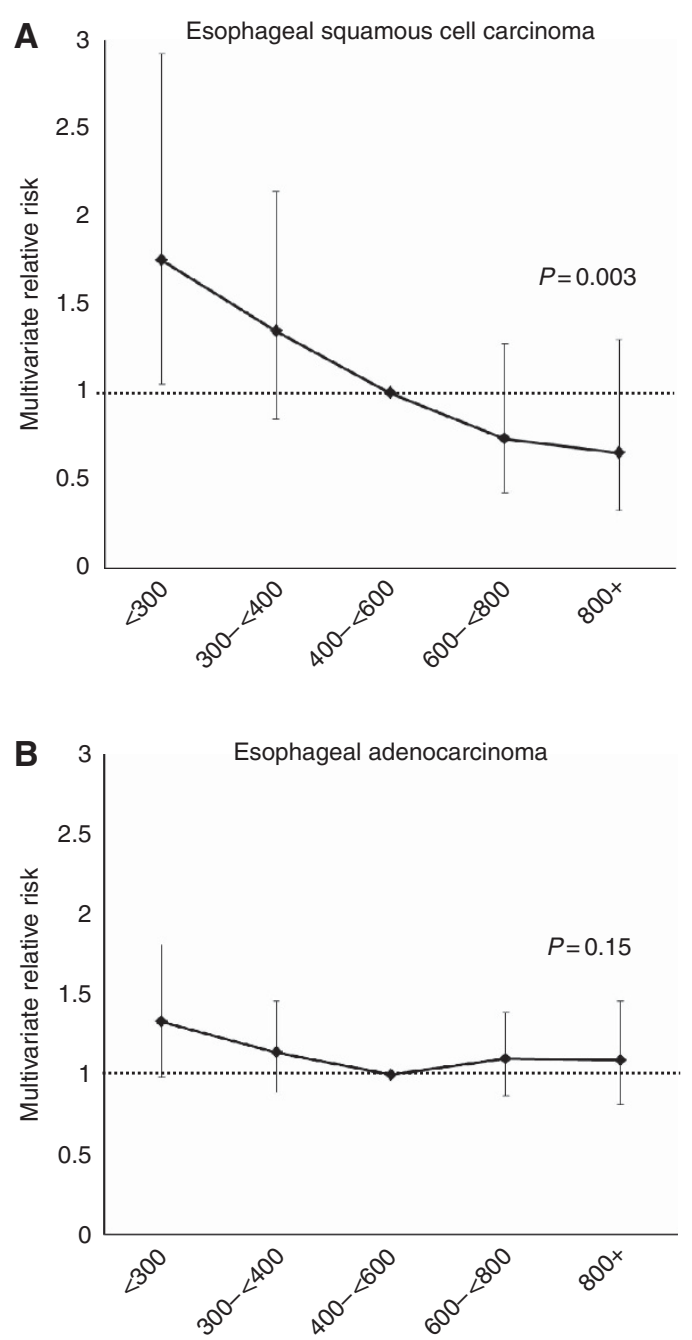

Figure 1. The multivariate association of total folate intake with esophageal squamous cell carcinoma and esophageal adenocarcinoma. Multivariate RRs and $95 \% \mathrm{Cls}$ of risk of (A) esophageal squamous cell carcinoma and (B) esophageal adenocarcinoma for categories of total intake (dietary and supplemental intake combined) of folate in the NIH-AARP study. Squares represent the HRs corresponding to each intake category. Vertical lines represent the $95 \% \mathrm{Cls}$. Models were adjusted for age at baseline (continuous); sex (male and female); race/ethnicity (nonHispanic white, non-Hispanic, black, and others); education (less than high school, high school graduate, some college and college graduate/ postgraduate); marital status (married, not married), health status (excellent, very good, good, fair, and poor); $\mathrm{BMI}(<18.5,18.5-<25$, $25-<30,30-<35, \geqslant 35 \mathrm{~kg} \mathrm{~m}^{-2}$ ); smoking status (never, former, and current); smoking dose $(0,1-10,11-20,21-30,31-40,41-50,51-60$, and $>60$ cigarettes per day); time since quitting (never quit, $\geqslant 10,5-9$, $1-4,<1$ years); vigorous physical activity (never/rarely; $\leqslant 3$ times per month; $1-2,3-4$, and $\geqslant 5$ times per week); alcohol $(0,<5,5-<15,15-$ $<30$, and $\geqslant 30 \mathrm{~g}$ per day); multivitamin use (nonuse, less than daily use, and daily use); family history of any cancer (yes or no), and total caloric intake (continuous). The numbers of cases were 19, 39, 36, 42, and 39 ESCC and 62, 121, 136, 132, and 68 EAC for categories of $<300,300$ $<400,400-<600,500-<800$, and $800+$ mcg per day, respectively.

strengths. This is the largest prospective study of folate and other B vitamin intakes with esophageal and gastric cancer to date. Also, our large sample size allowed us to study ESCC, EAC, GCA, and NCGA separately and evaluate folate effect by alcohol and smoking.
In conclusion, in this large cohort of US men and women, we found that low folate intake is associated with elevated risk of ESCC, but higher folate intake did not provide further reduction in ESCC risk. Additional prospective studies are needed to clarify the effect of folate and other nutrients in the one-carbon metabolism pathway on the risk of developing esophageal and gastric cancer. Large studies that assess the interrelation between folate intake, genetic polymorphism in folate pathway, and other factors such as alcohol and smoking would be particularly valuable.

\section{ACKNOWLEDGEMENTS}

This research was supported by the Intramural Research Program of the NIH, National Cancer Institute, Department of Health and Human Services. Cancer incidence data from the Atlanta metropolitan area were collected by the Georgia Center for Cancer Statistics, Department of Epidemiology, Rollins School of Public Health, Emory University, Atlanta, Georgia, USA. Cancer incidence data from California were collected by the California Cancer Registry, California Department of Public Health's Cancer Surveillance and Research Branch, Sacramento, California, USA. Cancer incidence data from the Detroit metropolitan area were collected by the Michigan Cancer Surveillance Program, Community Health Administration, Lansing, Michigan, USA. The Florida cancer incidence data used in this report were collected by the Florida Cancer Data System (Miami, Florida, USA) under contract with the Florida Department of Health, Tallahassee, Florida, USA. The views expressed herein are solely those of the authors and do not necessarily reflect those of the FCDC or $\mathrm{FDOH}$. Cancer incidence data from Louisiana were collected by the Louisiana Tumor Registry, Louisiana State University Health Sciences Center School of Public Health, New Orleans, Louisiana, USA. Cancer incidence data from New Jersey were collected by the New Jersey State Cancer Registry, Cancer Epidemiology Services, New Jersey State Department of Health, Trenton, New Jersey, USA. Cancer incidence data from North Carolina were collected by the North Carolina Central Cancer Registry, Raleigh, North Carolina, USA. Cancer incidence data from Pennsylvania were supplied by the Division of Health Statistics and Research, Pennsylvania Department of Health, Harrisburg, Pennsylvania, USA. The Pennsylvania Department of Health specifically disclaims responsibility for any analyses, interpretations, or conclusions. Cancer incidence data from Arizona were collected by the Arizona Cancer Registry, Division of Public Health Services, Arizona Department of Health Services, Phoenix, Arizona, USA. Cancer incidence data from Texas were collected by the Texas Cancer Registry, Cancer Epidemiology and Surveillance Branch, Texas Department of State Health Services, Austin, Texas, USA. Cancer incidence data from Nevada were collected by the Nevada Central Cancer Registry, State Health Division, State of Nevada Department of Health and Human Services, Las Vegas, Nevada, USA. We are indebted to the participants in the NIH-AARP Diet and Health Study for their outstanding cooperation. We also thank Sigurd Hermansen and Kerry Grace Morrissey from Westat for study outcome ascertainment and management and Leslie Carroll at Information Management Services for data support and analysis. Guarantor of the article: XQ.

\section{CONFLICT OF INTEREST}

The authors declare no conflict of interest. 


\section{AUTHOR CONTRIBUTIONS}

Study concept and design: QX and YP. Acquisition of data: ARH. Analysis and interpretation of data: QX, NDF, JR, CCA, and YP. Drafting of the manuscript: QX. Critical revision of the manuscript for important intellectual content: QX, NDF, JR, CCA, and YP. Statistical analysis: QX. Administrative, technical, and material support: ARH. Study supervision: YP.

\section{REFERENCES}

Bailey LB (1990) Folate status assessment. J Nutr 120(Suppl 11): 1508-1511.

Bailey LB (2003) Folate, methyl-related nutrients, alcohol, and the MTHFR $677 \mathrm{C}->\mathrm{T}$ polymorphism affect cancer risk: intake recommendations. J Nutr 133: 3748S-3753S

Botterweck AA, Van den brandt PA, Goldbohm RA (2000) Vitamins, carotenoids, dietary fiber, and the risk of gastric carcinoma: results from a prospective study after 6.3 years of follow-up. Cancer 88: 737-748.

Brown LM, Blot WJ, Schuman SH, Smith VM, Ershow AG, Marks RD, Fraumeni JF Jr (1988) Environmental factors and high risk of esophageal cancer among men in coastal South Carolina. J Natl Cancer Inst 80: $1620-1625$.

Brown LM, Swanson CA, Gridley G, Swanson GM, Schoenberg JB, Greenberg RS, Silverman DT, Pottern LM, Hayes RB, Schwartz AG, Liff JM, Fraumeni JF, Hoover RN Jr (1995) Adenocarcinoma of the esophagus: role of obesity and diet. J Natl Cancer Inst 87: 104-109.

Cook MB, Kamangar F, Whiteman DC, Freedman ND, Gammon MD, Bernstein L, Brown LM, Risch HA, Ye W, Sharp L, Pandeya N, Webb PM, Wu AH, Ward MH, Giffen C, Casson AG, Abnet CC, Murray LJ, Corley DA, Nyren O, Vaughan TL, Chow WH (2010) Cigarette smoking and adenocarcinomas of the esophagus and esophagogastric junction: a pooled analysis from the international BEACON consortium. J Natl Cancer Inst 102: 1344-1353.

Ibiebele TI, Hughes MC, Pandeya N, Zhao Z, Montgomery G, Hayward N, Green AC, Whiteman DC, Webb PM (2011) High intake of folate from food sources is associated with reduced risk of esophageal cancer in an Australian population. J Nutr 141: 274-283.

Jessri M, Rashidkhani B, Hajizadeh B, Gotay C (2011) Macronutrients, vitamins and minerals intake and risk of esophageal squamous cell carcinoma: a case-control study in Iran. Nutr J 10: 137.

Kamangar F, Chow WH, Abnet CC, Dawsey SM (2009) Environmental causes of esophageal cancer. Gastroenterol Clin North Am 38: 27-57. vii.

Kim HJ, Kim MK, Chang WK, Choi HS, Choi BY, Lee SS (2005) Effect of nutrient intake and Helicobacter pylori infection on gastric cancer in Korea: a case-control study. Nutr Cancer 52: 138-146.

La Vecchia C, Ferraroni M, D’Avanzo B, Decarli A, Franceschi S (1994) Selected micronutrient intake and the risk of gastric cancer. Cancer Epidemiol Biomarkers Prev 3: 393-398.

Larsson SC, Giovannucci E, Wolk A (2006) Folate intake, MTHFR polymorphisms, and risk of esophageal, gastric, and pancreatic cancer: a meta-analysis. Gastroenterology 131: 1271-1283.
Li WQ, Park Y, Wu JW, REN JS, Goldstein AM, Taylor PR, Hollenbeck AR, Freedman ND, Abnet CC (2013) Index-based dietary patterns and risk of esophageal and gastric cancer in a large cohort study. Clin Gastroenterol Hepatol 11(9): 1130-1136.e2.

Lopez-Carrillo L, Lopez-Cervantes M, Ward MH, Bravo-Alvarado J, Ramirez-Espitia A (1999) Nutrient intake and gastric cancer in Mexico. Int $J$ Cancer 83: 601-605.

Munoz N, Plummer M, Vivas J, Moreno V, de Sanjose S, Lopez G, Oliver W (2001) A case-control study of gastric cancer in Venezuela. Int J Cancer 93: 417-423.

Robinson WR, Keyes KM, Utz RL, Martin CL, Yang Y (2013) Birth cohort effects among US-born adults born in the 1980s: foreshadowing future trends in US obesity prevalence. Int J Obes (Lond) 37(3): 448-454.

Schatzkin A, Subar AF, Thompson FE, Harlan LC, Tangrea J, Hollenbeck AR, Hurwitz PE, Coyle L, Schussler N, Michaud DS, Freedman LS, Brown CC, Midthune D, Kipnis V (2001) Design and serendipity in establishing a large cohort with wide dietary intake distributions: the National Institutes of Health-American Association of Retired Persons Diet and Health Study. Am J Epidemiol 154: 1119-1125.

Shrubsole MJ, Shu XO, Li HL, Cai H, Yang G, Gao YT, Gao J, Zheng W (2011) Dietary B vitamin and methionine intakes and breast cancer risk among Chinese women. Am J Epidemiol 173: 1171-1182.

Stevens VL, Mccullough ML, Sun J, Gapstur SM (2010) Folate and other one-carbon metabolism-related nutrients and risk of postmenopausal breast cancer in the Cancer Prevention Study II Nutrition Cohort. Am J Clin Nutr 91: 1708-1715.

Subar AF, Midthune D, Kulldorff M, Brown CC, Thompson FE, Kipnis V, Schatzkin A (2000) Evaluation of alternative approaches to assign nutrient values to food groups in food frequency questionnaires. Am J Epidemiol 152: $279-286$.

Thompson FE, Kipnis V, Midthune D, Freedman LS, Carroll RJ, Subar AF, Brown CC, Butcher MS, Mouw T, Leitzmann M, Schatzkin A (2008) Performance of a food-frequency questionnaire in the US NIH-AARP (National Institutes of Health-American Association of Retired Persons) Diet and Health Study. Public Health Nutr 11: 183-195.

Ulrich CM (2007) Folate and cancer prevention: a closer look at a complex picture. Am J Clin Nutr 86: 271-273.

Willett W, Stampfer MJ (1986) Total energy intake: implications for epidemiologic analyses. Am J Epidemiol 124: 17-27.

Zhang ZF, Kurtz RC, Yu GP, Sun M, Gargon N, Karpeh Jr M, Fein JS, Harlap S (1997) Adenocarcinomas of the esophagus and gastric cardia: the role of diet. Nutr Cancer 27: 298-309.

Zhao P, Lin F, Li Z, Lin B, Lin J, Luo R (2011) Folate intake, methylenetetrahydrofolate reductase polymorphisms, and risk of esophageal cancer. Asian Pac J Cancer Prev 12: 2019-2023.

This work is published under the standard license to publish agreement. After 12 months the work will become freely available and the license terms will switch to a Creative Commons AttributionNonCommercial-Share Alike 3.0 Unported License.

Supplementary Information accompanies this paper on British Journal of Cancer website (http://www.nature.com/bjc) 